\title{
Development of an index to rank dairy females on expected lifetime profit
}

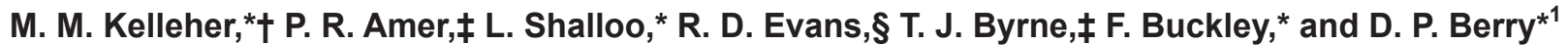 \\ ${ }^{*}$ Animal \& Grassland Research and Innovation Centre, Teagasc, Moorepark, Co. Cork, Ireland \\ †School of Agriculture and Food Science, University College Dublin, Belfield, Dublin 4, Ireland \\ $\ddagger$ AbacuBio LTD, Dunedin 9016, New Zealand \\ §lrish Cattle Breeding Federation, Bandon, Co. Cork, Ireland
}

\section{ABSTRACT}

The objective of this study was to develop an index to rank dairy females on expected profit for the remainder of their lifetime, taking cognizance of both additive and nonadditive genetic merit, permanent environmental effects, and current states of the animal including the most recent calving date and cow parity. The cow own worth (COW) index is intended to be used for culling the expected least profitable females in a herd, as well as inform purchase and pricing decisions for trading of females. The framework of the COW index consisted of the profit accruing from (1) the current lactation, (2) future lactations, and (3) net replacement cost differential. The COW index was generated from estimated performance values (sum of additive genetic merit, nonadditive genetic merit, and permanent environmental effects) of traits, their respective net margin values, and transition probability matrices for month of calving, survival, and somatic cell count; the transition matrices were to account for predicted change in a cow's state in the future. Transition matrices were generated from 3,156,109 lactation records from the Irish national database between the years 2010 and 2013. Phenotypic performance records for 162,981 cows in the year 2012 were used to validate the COW index. Genetic and permanent environmental effects (where applicable) were available for these cows from the 2011 national genetic evaluations and used to calculate the COW index and their national breeding index values (includes only additive genetic effects). Cows were stratified per quartile within herd, based on their COW index value and national breeding index value. The correlation between individual animal $\mathrm{COW}$ index value and national breeding index value was 0.65 . Month of calving of the cow in her current lactation explained $18 \%$ of the variation in the COW index, with the parity

Received November 5, 2014

Accepted February 6, 2015.

${ }^{1}$ Corresponding author: Donagh.Berry@teagasc.ie of the cow explaining an additional 3 percentage units of the variance in the COW index. Females ranking higher on the COW index yielded more milk and milk solids and calved earlier in the calving season than their lower ranking contemporaries. The difference in phenotypic performance between the best and worst quartiles was larger for cows ranked on COW index than cows ranked on the national breeding index. The COW index is useful to rank females before culling or purchasing decisions on expected profit and is complementary to the national breeding index, which identifies the most suitable females for breeding replacements.

Key words: genetic, heterosis, recombination, permanent environment

\section{INTRODUCTION}

Culling regimens can have a significant effect on dairy herd profit. Designing an optimal strategy to cull cows that are no longer profitable is not trivial and has been discussed extensively (Beaudeau et al., 1996; Weigel et al., 2003; Fetrow et al., 2006; Hadley et al., 2006). Excessive culling implies additional costs to generate the necessary replacement requirements, but also imposes subsequent losses in profit where the age profile of the herd is reduced (lower production capacity from primiparous cows compared with their mature herd mates). In contrast, delayed culling results in underperforming cows remaining in the herd while incurring opportunity costs by foregoing genetic gain and associated superior productive capacity from genetically superior replacement females.

Computerized culling models have facilitated the integration of scientific concepts in an attempt to mimic the reality of complex processes. Although significant advances in the development of these models have been made (Stewart et al., 1977; Ben-Ari et al., 1983; Dijkhuizen et al., 1986; Lopez-Villalobos et al., 2010; Nielsen et al., 2010), producers generally continue to rely on their own intuition for making culling decisions (Lehenbauer and Oltjen, 1998). Of the models that have been commercially implemented, including 
Dairy Comp 305 (Valley Agricultural Software, Tulare, $\mathrm{CA}$ ) and an economic cow value tool (http://dairymgt. info/tools/cow_value_resp/newindex.php), individual farm-specific data entry is required from the user. An opportunity exists to provide dairy producers with a means to rank cows on expected profitability and compare across herds without requiring additional data collection or entry.

An alternative tool could therefore aid producers in ranking animals on expected profit for the remainder of their lifetime, taking cognizance of factors intrinsic to maximize profit by maintaining optimal herd dynamics. To maximize the profit associated with the herd dynamics, the least-profitable animals are culled and more-profitable replacement animals, usually nulliparae, generated from the mating of genetically elite parents, are introduced. The selection of dams of the subsequent generation is generally based on additive genetic merit of the female and, in dairy cattle at least, this is predominantly based on an overall breeding goal ranking of the females. Although most national breeding goals incorporate the additive genetic merit for survival, culling decisions, in contrast, are based on a combination of genetic merit (additive and nonadditive genetic effects) and nongenetic factors, the latter including, for example, pregnancy status or expected calving date, udder health, and age of the animal. Nonadditive genetic effects (intra- and interlocus interactions) are not included in most national breeding goals; thus the expected performance of crossbred animals based on EBV may underestimate the actual future performance of an individual and expected lifetime profit. The superior performance of a crossbred individual relative to its parental mean performance, termed heterosis, is an artifact of increased genomic heterozygosity exploiting dominance variance, but also reducing the probability of homozygous recessive deleterious alleles affecting performance (Falconer and Mackay, 1996). Conversely, recombination loss is a consequence of loss in epistatic effects, where favorably linked loci that had previously produced a competitive advantage in certain traits due to generations of selection are broken down with further lines of crossbreeding, thereby reducing performance (Swan and Kinghorn, 1992). Nongenetic, permanent environmental effects also contribute to phenotypic variation. Such effects are environmental influences that permanently affect the individual's performance throughout its lifetime but are not transmitted to offspring (Kruuk and Hadfield, 2007).

The objective of the current study was to develop the framework for a tool to rank females on expected lifetime profitability, taking cognizance of total genetic merit (i.e., additive and nonadditive genetic merit) of the animal as well as both permanent and temporary (e.g., season of calving, parity) environmental effects. This tool will consider the profitability ensuing from (1) the current lactation and (2) future lactations, taking into consideration the future anticipated longevity of the animal, as well as (3) the implications for the herd replacement strategy. Providing producers with a tool to rank females, across ages, based on expected profit is essential in enabling more informed managerial decisions to distinguish between underperforming females to cull in the herd and females that should be retained or purchased.

\section{MATERIALS AND METHODS}

\section{Model Formulation}

The cow own worth (COW) model was developed to rank cows on expected lifetime profitability. The model comprised 3 main components: (1) expected profit in the current lactation $(\mathbf{C L})$; (2) expected profit in the future lactations (FL); and (3) net replacement cost differential (NRCD), calculated as

$$
\mathrm{COW}=\mathrm{CL}+\mathrm{FL}+\mathrm{NRCD} .
$$

$\boldsymbol{C L}$. Current lactation value describes the profit potential of the cow from a 305-d lactation (as per the current national genetic evaluation), given her current month of calving. The calculation of CL was:

$$
\mathrm{CL}=\pi_{\mathrm{MOC}}+\sum_{t=1}^{9} \mathrm{PNM}_{t} \cdot \mathrm{EPV}_{t},
$$

where CL is the expected profit output for the current lactation, given the current month of calving; $\pi_{\mathrm{MOC}}$ is the profit differential for current month of calving relative to a February calving (i.e., base) cow (Table 1); $t$ is a trait of the current lactation performance (milk yield, fat yield, protein yield, cull cow weight, milking speed, milking temperament, mastitis, lameness, and SCC; Table 2); $\mathrm{PNM}_{t}$ is the present net margin, using prevailing market prices and costs, associated with a one unit change in trait $t$ (Table 2); and $\mathrm{EPV}_{t}$ is the estimated performance value (EPV) for each of the 9 traits $t$ (described herein).

$\boldsymbol{F} \boldsymbol{L}$. Future lactation value describes the future profit potential of the cow over a 10-lactation horizon. Future profit in the present study was calculated as a function of the EPV for traits of economic importance, and the expected future survival, reproduction, and SCC transition probabilities, as well as profit accruing from dairy female descendants: 


$$
\begin{aligned}
& \mathrm{FL}=\sum_{i=i^{*}}^{i^{*}+10} s_{i}\left(\frac{1}{1+r}\right)^{\left(i-i^{*}\right)+1} \\
& \left(\sum_{t=1}^{14} \mathrm{FNM}_{t} \cdot \mathrm{EPV}_{t}+\sum_{j=1}^{5} P\left(\mathrm{MOC}_{\text {next }_{j}} \mid \mathrm{MOC}_{i^{*}}, \mathrm{EPV}_{\mathrm{CIV}}\right) \cdot \pi_{j}\right) \\
& +\sum_{k=1}^{3} P\left(\mathrm{SCC}_{\text {next }_{k}} \mid \mathrm{SCC}_{i^{*},} \mathrm{EPV}_{\mathrm{SCS}}, \text { Parity }\right) \cdot \alpha_{k}+D,
\end{aligned}
$$

where $s_{i}=P\left(\right.$ Survival $_{i} \mid \mathrm{MOC}_{i}$, Parity, $\left.\mathrm{EPV}_{\text {survival }}\right)$, and where FL is the sum of the profit for the arbitrarily chosen 10 subsequent lactations; $i^{*}$ is the lactation number of the initial lactation of the FL component, which is currently calculated as the lactation number for the next full lactation expected for the cow if not culled at the pending decision point for culling; $s_{i}$ is the survival probability from parity $i^{*}$ to parity $i$, where

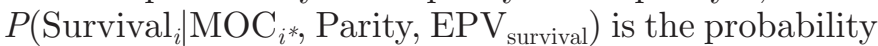
of surviving to the next lactation, given the current month of calving $\left(\mathrm{MOC}_{i^{*}}\right)$, current parity, and EPV group for survival $\left(\mathrm{EPV}_{\text {survival }}\right)$, modeled using matrices of transition probabilities derived from national data (described in detail later); $\frac{1}{1+r}$ is a discounting factor with an annual discount rate $(r)$ of $7 \%$ (Berry et al., 2006); $\mathrm{FNM}_{t}$ is the future net margin value based on estimates of future market prices and costs, associated with a 1-unit change in trait $t$ (Table 2); $\mathrm{EPV}_{t}$ is the estimated performance value of trait $t$, where $t$ is milk yield, fat yield, protein yield, cull cow weight, milking speed, milking temperament, mastitis, lameness, direct calving difficulty, maternal calving difficulty, calf mortality, progeny carcass conformation, progeny carcass fat, and progeny carcass weight; $P\left(\mathrm{MOC}_{\text {next }_{j}} \mid \mathrm{MOC}_{i^{*}}, \mathrm{EPV}_{\mathrm{CIV}}\right)$ is the probability of calving in the $j$ th month (January to May) in the following lactation, given the current month of calving $\left(\mathrm{MOC}_{i *}\right)$ and EPV group for calving interval $\left(\mathrm{EPV}_{\mathrm{CIV}}\right)$, described in detail herein; $\pi_{j}$ is the profit differential for each month of calving $j$ using future market prices, relative to the base month of calving, February (Table 1); $P\left(\mathrm{SCC}_{\text {next }_{k}} \mid \mathrm{SCC}_{i^{*},} \mathrm{EPV}_{\mathrm{SCS}}\right.$, Parity $)$ is the probability of the cow residing in the $k$ th SCC group in the next lactation, given the SCC group in the current lactation $\left(\mathrm{SCC}_{i^{*}}\right), \mathrm{EPV}_{\mathrm{SCS}}$ group, and parity, described using transition matrices; $\alpha_{k}$ is the profit differential for each SCC group $k$, derived from the mean difference of each SCC group multiplied by the future market cost for SCC, and relative to the average (i.e., base) SCC group (Table 1). There is an implicit assumption here that the probabilities of being in each of the future months of calving and future SCC categories will remain constant 
Table 2. Net margin values for the different components of the cow own worth index using prevailing 2014 or future market prices per unit change of each trait, derived from the Moorepark Dairy Systems Model (Shalloo et al., 2004)

\begin{tabular}{|c|c|c|c|}
\hline \multirow[b]{2}{*}{ Subindex } & \multirow[b]{2}{*}{ Trait $(t)$} & \multicolumn{2}{|c|}{ Net margin value $(€ /$ unit change in $t)$} \\
\hline & & Prevailing 2014 price $^{1}$ & Future price \\
\hline \multirow{2}{*}{ Production } & Fat $(\mathrm{kg})$ & 2.82 & 1.04 \\
\hline & Protein $(\mathrm{kg})$ & 8.07 & 6.64 \\
\hline \multirow[t]{2}{*}{ Calving } & Direct calving difficulty $(\%)$ & - & -3.52 \\
\hline & Maternal calving difficulty (\%) & - & -1.73 \\
\hline \multirow{3}{*}{ Beef } & Carcass weight $(\mathrm{kg})$ & - & 1.38 \\
\hline & Carcass conformation (grade) & - & 10.32 \\
\hline & Carcass fat $(\%)$ & - & -11.71 \\
\hline Maintenance & Cull cow weight $(\mathrm{kg})$ & -0.74 & -1.65 \\
\hline \multirow[t]{2}{*}{ Management } & Milking time (seconds) & -0.25 & -0.25 \\
\hline & Milking temperament (score) & 33.69 & 33.69 \\
\hline Health & Lameness $(\%)$ & -54.26 & -54.26 \\
\hline
\end{tabular}

${ }^{1}$ Prevailing 2014 price used for traits in the current lactation component of the COW index only (no values for calving and beef traits).

for the rest of the cow's life. Although this is an approximation, it greatly reduces the dimensionality of the transition probability matrices required, and insufficient industry data exists to estimate many of these probabilities without considerable error.

The value of future daughter replacements $(D)$ was calculated as

$$
D=\mathrm{EBI} \cdot \mathrm{CDE},
$$

where EBI is the national breeding goal value of the cow [economic breeding index (EBI); Berry et al., 2007, ICBF, 2014], and CDE is the cumulative discounted expressions for an annual trait and is assumed to be 0.89 (Berry et al., 2006). The EBI is based on PTA (i.e., expected performance of progeny). The cumulative discounted expressions accounts for the timing and frequency of expression of a trait, as well as the probability that a calf born becomes a dairy replacement.

Net Replacement Cost Differential. The NRCD was estimated as the savings in replacement costs (RC) net of cull cow salvage value (CSV) that would be retained if a cow in lactation $i$ was not culled;

$$
\mathrm{NRCD}_{i}=\left(1-\rho_{i}\right) \cdot(\mathrm{CSV}-\mathrm{RC})
$$

where $\rho_{i}$ is the long-term change in replacement requirements to maintain a stable herd structure if $1 \mathrm{cow}$ is culled at the end of parity $i$, and accounts for the fact that less replacements are required in the longterm when an older cow is culled, because older cull cows would need to be replaced soon anyway. The RC is the total cost of supplying an extra replacement to the herd. The CSV is the cull carcass value of a cow calculated as:

$$
\mathrm{CSV}=\mathrm{SV}+\mathrm{NM}_{\mathrm{CCW}} \cdot \mathrm{EPV}_{\mathrm{CCW}}
$$

where SV is the average salvage value for a cull cow; $\mathrm{NM}_{\mathrm{CCW}}$ is the net margin value per kilogram for cull cow weight (Table 2); $\mathrm{EPV}_{\mathrm{CCW}}$ is the estimated performance value for cull cow weight.

\section{EPV}

The EPV of each animal were calculated as the sum of the EBV, heterosis and recombination loss contribution, and permanent environment effect (where considered in the genetic evaluation model). An adjustment was made to the EBV and permanent environmental effects for milk production traits to rescale from mature equivalents; EBV and permanent environment effects for cows in parity 1 and 2 were divided by a factor of 1.22 and 1.07 , respectively, based on calculations undertaken on the milk production parity effects documented by Horan et al. (2005) for Irish dairy cows.

\section{Transition Matrices}

A transition matrix uses past information to estimate the probability of transition from one state to another, over time. This is known as the Markovian property (Gamerman and Lopes, 2006). Transition probabilities were calculated using national data between the years 2010 and 2013 (data described herein). Calving date for the current lactation was grouped by calendar month. 
The probability of a cow remaining in her current state or transitioning to another state in the subsequent lactation, or transition matrix, was estimated for (1) calving month, (2) survival to the next lactation, and (3) lactation average SCC. The current state was current month of calving for the calving month and survival transition matrix, and current SCC group for the SCC transition matrix. Cow EPV for calving interval, survival, and SCC were categorized into 10 percentile groups.

(1) Calving Month Transition Matrix. A 2-dimensional 12 (month of calving in current lactation; January to December) $\times 5$ (month of subsequent calving; January to May representing spring calving) transition matrix was constructed. The probability of calving in a spring month in the subsequent lactation was calculated given the actual calving month in the current lactation. This 2-dimensional transition matrix was calculated for each of the 10 calving interval EPV groups, thereby producing a 3 -dimensional array $(12 \times$ $5 \times 10)$.

(2) Survival Transition Matrix. Cows were assumed to have survived from one lactation to the next where a calving date existed for the subsequent lactation. A cow was considered not to have survived to the subsequent lactation if she did not recalve within 450 $\mathrm{d}$ of her herd's last recorded calving date or the date of calving in the subsequent lactation was after May 31; such a strict criterion was imposed to reflect the seasonal calving system in Ireland (Berry et al., 2013). Cows without a most recent calving date within $450 \mathrm{~d}$ of the date of data extraction were coded as missing, as it was uncertain as to whether these cows were due to calve or were involuntarily culled at this time. For firstparity cows, only calving dates for cows aged between 21 and 30 mo at the time of calving were retained. Cows older than or equal to parity 6 were grouped together.

A 2-dimensional 12 (month of calving in current lactation; January to December $) \times 6$ (parity; 1 to $6+$ ) transition matrix was constructed. This 2-dimensional transition matrix was calculated for each of the 10 survival EPV groups thereby producing a 3-dimensional array $(12 \times 6 \times 10)$.

(3) SCC Transition Matrix. A 2-dimensional 3 (SCC group in the current lactation) $\times 3$ (SCC group in subsequent lactation) transition matrix was constructed. Cows were grouped into $3 \mathrm{SCC}$ categories, $\leq 150,000$ cells $/ \mathrm{mL}$ (group 1), 150,001 to 400,000 cells/ $\mathrm{mL}$ (group 2), and $\geq 400,000$ cells $/ \mathrm{mL}$ (group 3 ). This 2-dimensional transition matrix was calculated for each of the 10 SCS EPV groups, thereby producing a 3-dimensional array $(3 \times 3 \times 10)$. This was constructed for 6 parities, where cows older than or equal to parity 6 were grouped together.

\section{Replacement Probabilities}

The long-term change in replacement requirements for a herd of constant cow numbers over time was modeled to obtain values for $\rho_{i}$ used in the calculation of the net replacement cost differential value. Long-term replacement implications are dependent on the age of individual cows culled. Culling an older cow effectively makes the average age of the herd younger, and the converse is true where a younger cow is culled. A younger herd will require less total future replacements than an older herd. Values of $\rho_{i}(0.9,0.76,0.66$, and 0.56 for parities $1,2,3$, and $>3$, respectively) were calculated using the same method and values described in Amer et al. (2001).

\section{Data}

Calving dates of 3,156,109 Irish dairy lactations from spring-calving herds (herd size $\geq 50$ ) were extracted from the Irish Cattle Breeding Federation (ICBF) database for the years 2010 to 2013, inclusive. Phenotypes for SCC were also extracted for the years 2010 to 2013 , inclusive, and were log-transformed. Only herds with $\geq 80 \%$ of cows calved within the first 5 mo of the year were included to represent spring-calving herds, which is the predominant production system in Ireland (Berry et al., 2013). Individual animal EBV for traits included in the EBI, from the April domestic genetic evaluations in 2011, were used. Genetic evaluations for 305-d milk, fat, and protein yield, as well as SCS (natural logarithm of SCC) were undertaken by the ICBF using a multibreed repeatability model; therefore, individual animal permanent environmental effects were also available for these traits. A multitrait, multibreed animal model was used in the genetic evaluations of reproductive performance and survival, as well as the genetic merit of calving performance and beef performance (Berry et al., 2006, 2007, 2013; Pabiou et al., 2012) A multibreed animal repeatability model was used for management performance traits and a univariate multibreed animal repeatability model was used for genetic evaluations of health traits (Berry et al., 2007; ICBF, 2014; Table 2). Heterosis and recombination loss coefficients for each animal and their respective regression coefficients associated with each of the performance traits were also available for all traits included in the national genetic evaluation (Ahlborn-Breier and Hohenboken, 1991).

\section{Economic Parameters}

The effect on net margin for traits to be considered in the COW index were obtained from the Moorepark Dairy Systems Model (MDSM; Shalloo et al., 2004) 
for a prevailing (i.e., in the present study the year 2014 was chosen) price and future price scenario (Tables 1 and 2). The MDSM is a stochastic budgetary simulation model that simulates the economic consequences from a comprehensive integration of herd performance, nutritional requirements, land use, and total inputs and outputs annually for spring-calving, grass-based milk production systems. The model assumes that cows are fed a predominantly grass-based diet. The MDSM adopts the net energy requirements system (Jarrige, 1989) for milk production, maintenance, pregnancy, and BW change, with adjustments for different proportions of feed (grass, grass silage, and concentrate).

Profit differences between optimum calving (early calving; January 15 to February 28, inclusive) and later spring-calving months were also defined from the MDSM, assuming cows were dried off on December 1. The prevailing 2014 price was set at $34.5 \mathrm{c} / \mathrm{L}$ and was calculated from the average milk price over 2 mo (July and August) in 2014, from 2 Irish milk processors (LTO, 2014). For future pricing, cows were assumed to produce for $305 \mathrm{~d}$ per lactation and the milk price was set at $29.5 \mathrm{c} / \mathrm{L}$ (Shalloo et al., 2014); this is consistent with what is currently used in the Irish national breeding goal, the EBI. Net margin values used in the calculation of the NRCD value included the cost of a replacement heifer with a value of $€ 1,545$ and the average salvage value for a cull cow of $€ 484$ (Shalloo et al., 2014).

\section{Index Evaluation}

Individual cow EBI values and $\mathrm{COW}$ index values were generated using the information (individual cow PTA, permanent environmental effects, heterosis coefficients, recombination loss coefficients for economically important traits, as well as parity and month of calving) from the April 2011 national genetic evaluations; only cows residing in spring-calving herds with $\geq 50$ cows were retained. Cows were categorized, within herd, into 4 groups based on their value for either the COW or EBI index. Only cows that had phenotypic performance data for milk production traits (milk yield, fat yield and percentage, protein yield and percentage, and SCS), fertility (between 300 and $600 \mathrm{~d}$ ), and survival for the calendar year 2012 were retained. Survival from the year 2011 to 2012 was defined as whether or not a cow had survived to the next lactation by the presence (survival $=1$ ) or absence (survival $=0$ ) of a calving date within the spring calving season (calving date between January and May) of the subsequent lactation. After editing, COW values and EBI values, as well as phenotypic performance data, were available on 162,981 cows in 2,077 herds.
The association between month of calving and parity with the dependent variables of either the COW or EBI index was quantified using a fixed effects linear model in PROC GLM (SAS Institute, 2011). A fixed effects linear model was used to determine the mean COW and EBI values of purebred Holstein, Friesian, and Jersey. The fixed effects included parity, breed proportion (Holstein breed proportion was not included in the model to avoid linear dependencies), and breed-specific heterosis effects for Holstein-Friesian, Holstein-Jersey, and Friesian-Jersey.

A fixed effects linear model was also used to quantify the association between each quartile of the COW and EBI index separately (independent variable) with milk, fat and protein yield, as well as SCS (dependent variable) in the year 2014 using PROC GLM (SAS Institute, 2011). The logit of the probability of survival to the next lactation was modeled using logistic regression in PROC GENMOD (SAS Institute, 2011). Quartiles for the COW or EBI index as well as parity were included as fixed effects in the model.

\section{RESULTS}

\section{Transition Matrices}

The probability of calving in each calendar month in the subsequent lactation, given the current month of calving, for the best decile and worst decile EPV cows for calving interval is presented in Figure 1. The complete transition matrix is provided in Supplementary Table S1 (http://dx.doi.org/10.3168/jds.20149073). The highest EPV cows for calving interval had a greater probability of recalving earlier in the spring calving season (February) compared with the lowest EPV cows. February-calving cows in the top decile EPV for calving interval were more likely (an additional 15 percentage units) to calve the following February or earlier compared with the bottom decile EPV for calving interval. The majority (89\%) of the top decile EPV cows were expected to have calved by the end of March of the following year, whereas only $79 \%$ of the bottom decile EPV cows were expected to calve by the end of March.

The probability of surviving to the next lactation for cows in the best decile and worst decile on EPV for survival is presented in Figure 2 (see Supplementary Table S2 for the complete transition matrix; http:// dx.doi.org/10.3168/jds.2014-9073). Younger cows had a greater probability of surviving to the next lactation compared with older cows of the same EPV for survival. The highest decile EPV cows had the greatest probability of surviving to the next lactation across all combinations of month of calving and parity (Figure 


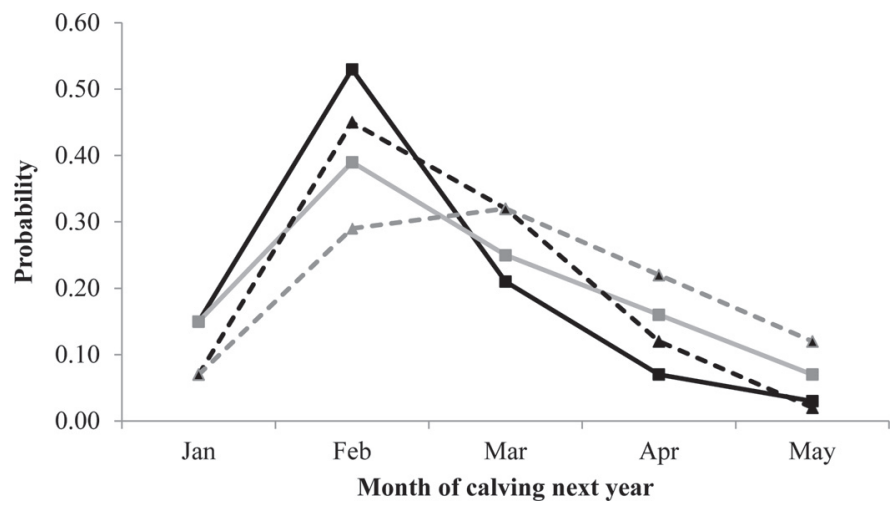

Figure 1. Probability of calving in a given month in the subsequent lactation for the top $10 \%$ estimated performance value (EPV) cows (black) and bottom 10\% EPV cows (gray) calving in the current lactation in February (solid lines) or March (dashed lines).

2). For example, the highest decile EPV, Februarycalving, primiparous cows were more likely (an additional 22 percentage units) to survive to the next lactation compared with worst decile EPV, primiparous, February-calving cows. Fewer than half the parity 5, April-calving cows in the worst decile for EPV were expected to survive to the next lactation; the corresponding statistic for parity 5 April-calving cows in the top decile was $81 \%$. The probability of surviving to the next lactation diminished rapidly for cows calving later in the calving season (April onward); for example, a 21-percentage-unit difference was observed in survival to the next lactation for the best decile EPV, Aprilcalving, parity 5 cows compared with the best decile EPV, June-calving, parity 5 cows ( 81 and $60 \%$ survival rate to the next lactation, respectively).

The probability of a cow transitioning between a phenotypically low SCC to a phenotypically high SCC for parity 3 cows in the best and worst decile on EPV SCS is presented in Figure 3 (see Supplementary Table S3 for complete transition matrix; http://dx.doi. org/10.3168/jds.2014-9073). The highest decile EPV cows had a greater probability of having a low SCC in the subsequent lactation, irrespective of SCC in the current lactation. For example, $91 \%$ of the low-SCC cows in the top decile SCS EPV were expected to reside in the low SCC category in the subsequent lactation, and $84 \%$ of high-SCC cows in the top decile SCS EPV were also expected to reside in the low SCC category in the subsequent lactation. High-SCC cows in the bottom decile SCS EPV were less likely (an additional 66 percentage units) to have low SCC in the subsequent lactation compared with high SCC cows in the top decile SCS EPV (18 and $84 \%$ probability of low SCC in the subsequent lactation, respectively). Over half of

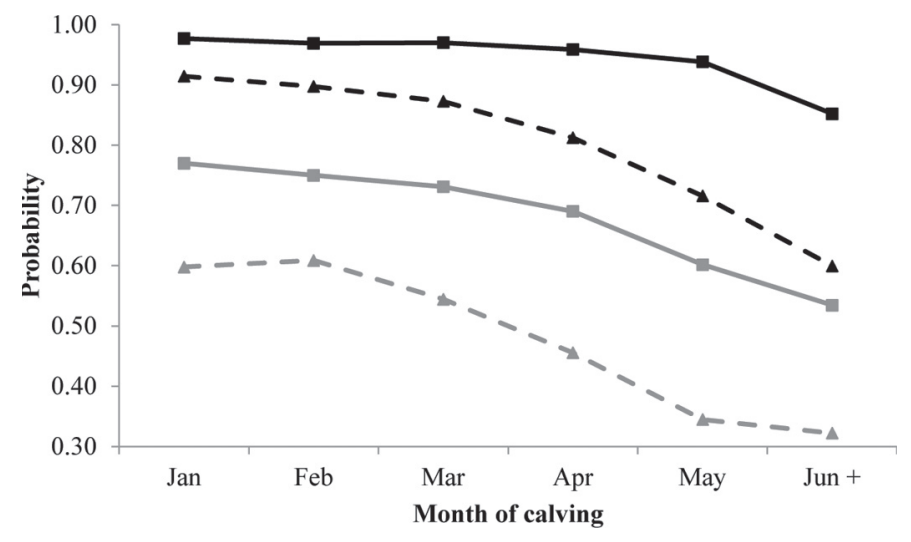

Figure 2. Probability of surviving to the next lactation given the month of calving in the current lactation for the top $10 \%$ estimated performance value (EPV) cows (black) and bottom 10\% EPV cows (gray) for survival for parity 1 (solid lines) and parity 5 (dashed lines) cows.

high-SCC cows in the bottom decile SCS EPV were expected to remain in the high SCC category in the next lactation.

\section{COW Index}

Descriptive statistics for the COW index and its components are in Table 3. Across all herds, the COW index was moderately positively correlated $(\mathrm{r}=0.65)$ with the EBI; within a herd the correlation between COW and EBI varied from 0.08 to 0.89 . The standard deviation for the COW index was almost 10 times the standard deviation of the EBI. The standard deviation for the FL was almost twice as large as that of the CL. Of the 3 components contributing to the COW

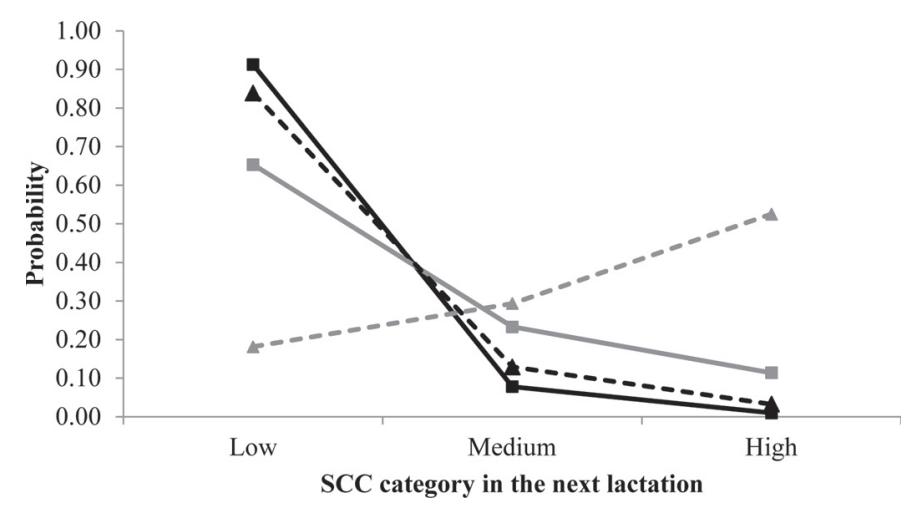

Figure 3. Probability for low SCC (solid lines) and high SCC (dashed lines) cows in the current lactation residing in the low $(\leq 150,000$ cells $/ \mathrm{mL})$, medium $(150,001-400,000$ cells $/ \mathrm{mL})$, or high $(\geq 400,000$ cells $/ \mathrm{mL})$ SCC category in the subsequent lactation for the top $10 \%$ estimated performance value (EPV) cows (black) and bottom $10 \%$ EPV cows (gray) for SCC, respectively, in parity 3 cows. 
Table 3. Mean ( $\mu$ ), SD, and correlations between the national genetic evaluation index (EBI), the cow own worth $(\mathrm{COW})$, and each of the COW index components: current lactation (CL), future lactation plus descendants (FL), and net replacement cost differential (NRCD)

\begin{tabular}{lrrrrr}
\hline Item & EBI & COW & CL & \multicolumn{1}{c}{ FL } & \multicolumn{1}{c}{ NRCD } \\
\hline$\mu(€)$ & 115.46 & 100.51 & -30.61 & 432.20 & -301.08 \\
SD $(€)$ & 53.45 & 509.54 & 189.54 & 349.17 & 141.40 \\
EBI & & 0.65 & 0.28 & 0.74 & 0.11 \\
COW & & 0.82 & 0.93 & 0.22 \\
CL & & & 0.68 & -0.06 \\
FL & & & & -0.05 \\
\hline
\end{tabular}

index, the FL component had the strongest correlation $(\mathrm{r}=0.93)$ with the COW index. Both the CL and FL were strongly positively correlated $(\mathrm{r}=0.68)$ with each other.

Correlations between both the COW and EBI index with both additive genetic merit (PTA) and phenotypic performance for a range of traits are presented in Table 4. The COW index had a moderate to strong correlation (0.24 to 0.51) with genetic merit for milk yield, fat percentage, and protein percentage. The EBI was more strongly correlated with genetic merit for calving interval and survival than the COW index.

The current month of calving explained $18 \%$ of the variance in the COW index, and $21 \%$ of the variance in the COW index was explained by both parity and current month of calving combined. Current month of calving explained only $1 \%$ of the variance in the EBI index; current month of calving and parity together explained only $2 \%$ of the variance in EBI.

Primiparous cows ranked higher $(P<0.001)$ on both the COW and EBI index than their older contemporaries. The mean $\mathrm{COW}$ value decreased with later calving in the calving season, for both parity 1 and 5 cows (Figure 4). For example, primiparous cows calving in April are expected to be $€ 409$ less profitable than primiparous cows calving in February. The difference in average EBI between extreme months of calving or between extreme parities was less than the differences in COW index values between the extremes; cows calving in February had, on average, a $€ 10$ greater EBI compared with cows calving in April, and primiparous cows had, on average, a €13 greater EBI compared with parity 5 cows.

A comparison between the EBI and COW index values for cows within a randomly chosen herd $(\mathrm{n}=169$ cows) from the national database is presented in Figure 5. A positive correlation $(\mathrm{r}=0.66)$ existed between the EBI and COW values. The majority of the highestranking cows on the COW index calved in February. An example of the disparity between the indices was where a cow ranking in the lowest $15 \%$ for EBI was ranked in the top $15 \%$ for $\mathrm{COW}$ in the herd on the
COW index. Details of the cow's performance in 2012 revealed that this second-parity cow calved early in the calving season (February), produced $7,704 \mathrm{~kg}$ of milk containing $609 \mathrm{~kg}$ of milk solids, and resided in the low SCC category. The cow with the highest COW value had an EBI €59 less than that of the best EBI cow, whereas the second-best cow on the COW index had $€ 95$ less of an EBI relative to the best EBI cow.

Breed effects and breed-specific heterosis effects for first-generation crossbred cows were estimated for the COW and EBI index (Table 5). The COW value of Holstein cows was superior $(P<0.001)$ to Friesian cows but less $(P<0.001)$ than Jersey cows. Jersey cows were superior $(P<0.001)$ compared with the other breeds on EBI. The breed-specific heterosis effects were positive for both indices. One hundred percent heterosis (i.e., from a first cross) from a Friesian-Jersey cross $(€ 597)$ had the greatest $(P<0.001)$ COW value compared with a Holstein-Jersey cross $(€ 472)$ and a Holstein-Friesian cross (€245). Heterosis effects on EBI were small.

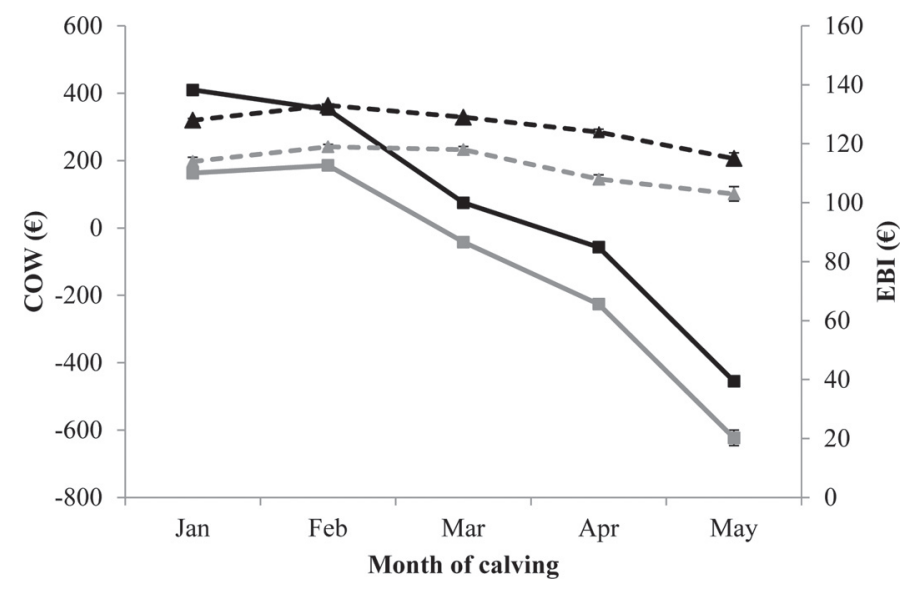

Figure 4. Mean (SE) cow own worth (COW; solid line) and economic breeding index (EBI; dashed line) for each month of calving, for parity 1 (black) and parity 5 cows (gray). 
Table 4. Correlations between both the cow own worth (COW) and economic breeding index (EBI) with both genetic merit and phenotypic performance for a range of traits

\begin{tabular}{lrrrrr}
\hline & \multicolumn{2}{c}{ COW } & & \multicolumn{2}{c}{ EBI } \\
\cline { 2 - 3 } \cline { 5 - 6 } Item & Genetic & Phenotypic & & Genetic & Phenotypic \\
\hline Milk (kg) & 0.24 & 0.06 & & -0.11 & -0.18 \\
Fat (\%) & 0.51 & 0.18 & & 0.27 & 0.26 \\
Protein (\%) & 0.51 & 0.30 & & 0.16 & 0.33 \\
SCC & -0.17 & -0.12 & & -0.15 & -0.11 \\
Calving interval (d) & -0.22 & -0.01 & & -0.73 & -0.14 \\
Survival (\%) & 0.28 & 0.20 & & 0.74 & 0.22 \\
\hline
\end{tabular}

\section{Comparison of Cows Stratified on COW or EBI}

Mean parity number per quartile of the COW index was $3.06,3.18,3.47$, and 3.91 in order of decreasing COW index ranked from the top to the bottom quartile. The lowest-ranking cows (bottom quartile) on the COW index yielded the least $(P<0.001)$ amount of milk; cows in the top quartile yielded $801 \mathrm{~kg}$ more milk than the lowest quartile of cows ranked on the COW index (Table 6). Similarly, the worst quartile of cows ranked on the COW index had a lower milk fat and protein concentration, and a greater SCC, than all other quartiles $(P<0.001)$. When cows were ranked using the COW index, cows produced 39,25 , and 17 $\mathrm{kg}$ more $(P<0.001)$ fat, 37,24 , and $12 \mathrm{~kg}$ more $(P$ $<0.001)$ protein, and 76, 62, and 32 thousand cells per milliliter less $(P<0.001)$ SCC, respectively, when the highest to lower quartiles were compared with the lowest quartile.

Although a statistical difference $(P<0.001)$ in mean parity number per quartile of the EBI existed, the biological difference was relatively small: $3.30,3.32,3.42$, and 3.57 in order of decreasing EBI ranking from the top to the bottom quartile. Cows ranked in the lowest quartile for the EBI produced $207 \mathrm{~kg}$ less $(P<0.001)$ milk than cows ranked in the highest quartile on the EBI; relative to the lowest quartile of cows ranked on the EBI, cows in higher-ranking quartiles, in order of best to worse, produced 20,12 , and $7 \mathrm{~kg}$ more $(P<$ $0.001)$ fat, 16,10 , and $6 \mathrm{~kg}$ more $(P<0.001)$ protein, and 56, 37, and 23 thousand cells per milliliter less $(P$ $<0.001)$ SCC, respectively.

Relative to the lowest COW quartile, the odds (95\% confidence intervals in parentheses) of a cow in the highest COW quartile surviving to the next lactation was 2.89 (2.78-3.00); the odds ratio for the corresponding comparison of cows divergent for EBI was 3.10 (2.98-3.22). Cows calving earlier in the spring were more likely to rank higher for both COW and EBI (Figure $6 \mathrm{a}$ and $6 \mathrm{~b}$ ). A greater proportion of the top quartile of cows on the COW index calved early in the season compared with the top quartile of cows on the EBI.

\section{DISCUSSION}

The motivation for the development of a ranking tool, supplementary to the current national breeding index, was that cows expressing favorable nonadditive genetic effects (heterosis) as well as favorable environmental effects (calving at the optimal time of the year, positive permanent environmental effects) should be rewarded, as they will, on average, yield more profit for the remainder of their lifetime. Such a tool is particularly timely, as the exploitation of crossbreeding programs in some populations intensifies, such as Denmark (Sørensen et al., 2008) and New Zealand (LIC, 2014 ); but also as reproductive performance improves in many populations (Berry et al., 2014) and the scope for voluntary culling increases.

Table 5. Mean breed effects relative to the Holstein for the cow own worth (COW) and economic breeding index (EBI), and breed-specific heterosis effects for the lifetime of a cow for the COW (below diagonal) and EBI index (above diagonal) ${ }^{1}$

\begin{tabular}{llccc}
\hline Item & Subset & Holstein & Friesian & Jersey \\
\hline Mean $(€)$ & COW & 0 & -84 & 263 \\
Heterosis $(€)$ & EBI & 0 & 50 & 83 \\
& Holstein & 245 & 23 & 28 \\
& Friesian & 472 & 597 & 74 \\
\hline
\end{tabular}

${ }^{1}$ All effects statistically significant $(P<0.001)$. 


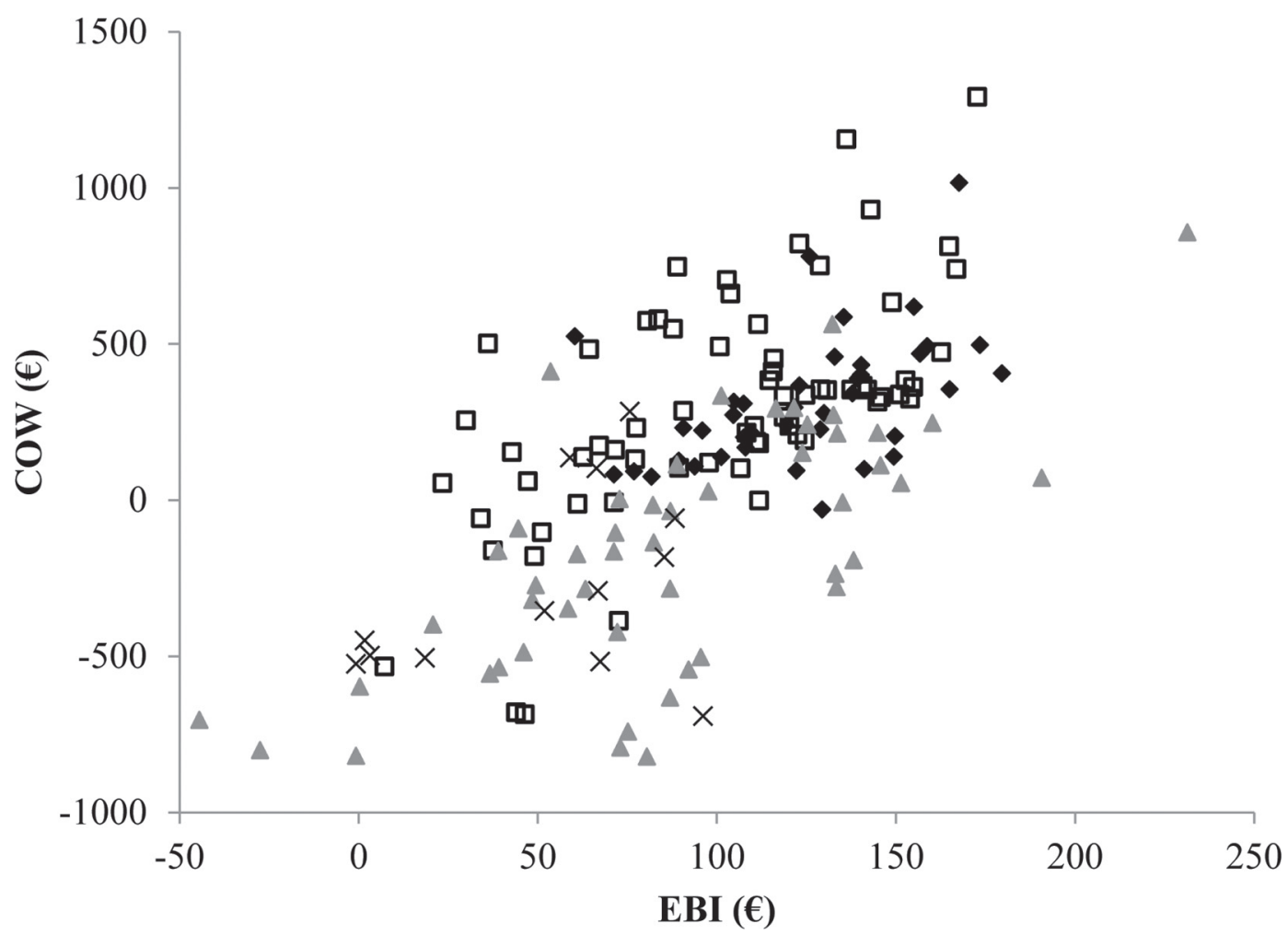

Figure 5. Scatterplot between the cow own worth $(\mathrm{COW})$ and economic breeding index (EBI) values by month of calving $($ January $=\bullet$; February $=\square ;$ March $=\boldsymbol{\Delta}$; April $=\times$ ) for an example herd from the national database $(\mathrm{n}=169$ cows $)$.

The COW index is not a proposed replacement for the national breeding goal, the EBI. Furthermore, the COW index is not generated for males. It can be generated for all females. The EBI of an individual is composed of the additive genetic merit of that individual and thus reflects the contribution of that individual to the expected performance of its progeny; this, therefore, is a suitable index for the identification of genetically elite females (and males) as parents of the next generation. The COW index incorporates additional phenotypic information such as calving date and cow parity as well as nonadditive genetic merit and permanent environmental merit. The COW index, however, recognizes that the phenotypic performance of an individual is also partly determined by the individual's additive genetic merit; this is reflected in the positive correlation (0.65) between the EBI and COW index owing to the part-whole relationship between both indices. Thus, the EBI index is an aid in the identification of parents of the next generation whereas the COW index is for the identification of females for culling or for purchasing. The unsuitability of the COW index as a tool for identifying females as parents of the next generation is substantiated by the differential in profit between different months of calving (Table 1); if, for example, a producer failed to detect a cow in estrus it would reduce her current lactation expected profit by $€ 210$ if this meant a slippage from March calving to April calving.

\section{Formation of the COW Index}

The COW index was designed to reflect the future anticipated profit of a cow based on factors such as additive genetic merit, nonadditive genetic merit, permanent environmental effects, calving month, expected subsequent calving month, and parity. A somewhat similar index, Production Worth (Harris, 2005), exists in New Zealand and ranks cows on expected future profitability and is proposed for use in the culling and purchasing of cows. Production Worth includes the additive genetic merit, heterosis, and permanent environmental effects for milk yield, fat yield, protein yield, and live weight (Clark et al., 2013). It does not, however, consider any measure of reproductive performance either at a genetic or phenotypic level nor does it consider the age of the cow or the month of calving, both of which influence culling decisions (Berry et al., 2005); this is possibly why Production Worth is more strongly correlated (0.79; Clark et al., 2013) with 

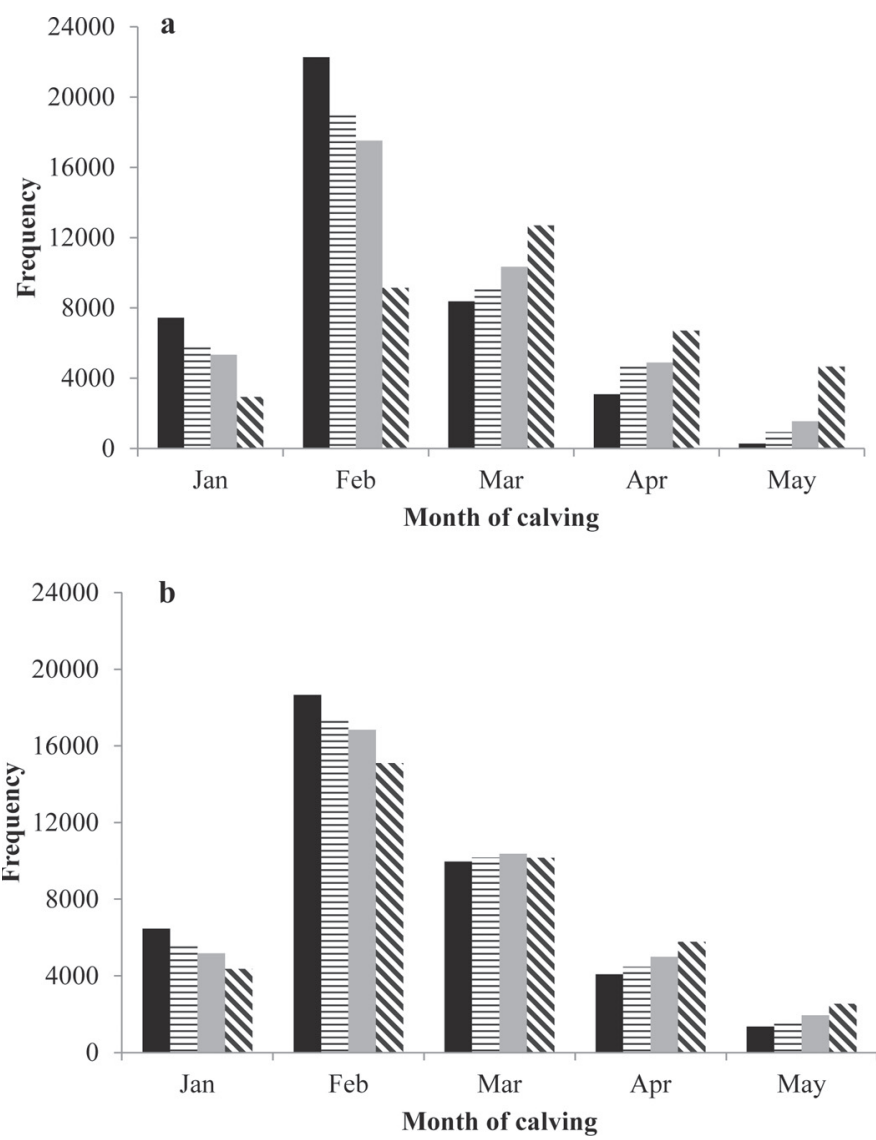

Figure 6. Month of calving frequencies for each quartile on the cow own worth (COW; a) and economic breeding index (EBI; b) index (in order of best to worst; solid black, horizontal lines, solid gray, and diagonal lines).

their national breeding goal, Breeding Worth, than the correlation observed in the present study between the COW and EBI indices. Lactation Worth, as used in New Zealand (Harris, 2005), ranks cows on current season performance only and is analogous to CL as defined in the present study, although Lactation Worth does not consider the effect of the current month of calving on the expected lactation performance of the animal.

Although the heritability of reproductive performance is low (Berry et al., 2014), total genetic merit (additive plus nonadditive genetic merit) does nonetheless affect the transition probabilities from the current calving month to the month of calving in the subsequent lactation. Moreover, the consequence of calving month, irrespective of genetic merit, is of huge economic importance in seasonal calving systems (Shalloo et al., 2014), such as exists in Ireland (and New Zealand), where the majority of cows calve in the spring (Berry et al., 2013) coinciding with the initiation of grass growth. For example, based on the MDSM, a cow calving in May will, on average, be $€ 522$ less profitable than the same cow 
calving in February. The reduced profit of the latercalving cow is predominantly due to a shorter lactation length (due to a fixed dry off date; December 1 in the present study). Therefore, reproductive performance, both the current month of calving and the expected future month of calving, is a crucial component in the expected lifetime profit of a cow. This is emphasized by the large relative contribution of month of calving to the variation among cows in COW value. It is important to note that the genetic capacity of a cow to bring forward her calving date, even if she is not calving in the most optimum time period in the current lactation, is accounted for in the COW index using calving month transition matrices.

The true breeding value of an animal does not vary with age, yet the expected profitability will vary due to the remaining longevity expected for younger versus older cows. The expected lifetime of older animals is, on average, less than that of younger animals (Figure 2 ), and older animals represent a smaller proportion of a first lactation equivalent than younger animals (Amer et al., 2001). Therefore, it is necessary to take into account that fewer replacements are required in the long term when an older cow is culled because older cows would need to be replaced in due course anyway. It is also important to recognize that a poor-performing young cow will continue to be a poor performer for more years than an equivalent older cow with less years remaining. Additionally, reducing the age profile of the herd will reduce herd performance due to the removal of older cows at the height of their productive ability. The salvage value from culling cows is put toward the expense associated with the generation of a replacement heifer. Therefore, if a producer chooses to retain the older cow, the associated cost of replacement is reduced, until the cow is at the end of her productive life, where she will be replaced with a 2-yr-old replacement heifer anyway. Therefore, parity has a major influence on the future profitability of cows, irrespective of the genetic merit of the animal, and should be included where an index is used to rank cows on expected profitability.

The narrow-sense heritability of milk production is approximately 0.3 but the repeatability is greater than 0.5 , suggesting that approximately $20 \%$ of the phenotypic variation is due to permanent environmental effects (Veerkamp and Brotherstone, 1997; Berry et al., 2003). Furthermore, although the narrowsense heritability for reproductive performance is low (Berry et al., 2014), Hoeschele (1991) estimated that the broad-sense heritability (where the numerator of heritability includes both additive and nonadditive genetic variation) can be at least twice the narrow sense heritability. Heterosis effects for milk production traits are approximately $4 \%$ of the mean (Penasa et al., 2010). Buckley et al. (2014) documented that heterosis in Holstein-Friesian crosses increases the probability of a cow having a calf born to AI during the calving period by $3.4 \%$. Therefore, considering only additive genetic merit of an individual in an index to rank the profitability of cows would bias against, in particular, crossbred animals displaying heterosis or animals with positive permanent environmental effects. This was substantiated by the large potential gains achievable in an $\mathrm{F}_{1}$ crossbred cow (Table 5). A Friesian-Jersey $\mathrm{F}_{1}$ crossbred cow is expected, on average, to be $€ 597$ more profitable than her parental mean, compared with an average of $€ 245$ more profit than the parental mean from a Holstein-Friesian $\mathrm{F}_{1}$ crossbred cow, thus reflecting the genetic distance between the purebred parents (Harris et al., 2014).

\section{Performance of Animals Ranked on COW}

Stratification of the COW and EBI indices into 4 quartiles highlighted significant differences in cow performance between the indices. Cows ranked in the top quartile on the COW index produced $291 \mathrm{~kg}$ more milk than the top quartile on EBI. Considering the prevailing milk price of 34.5 cents per liter, the top quartile cows in the COW index are expected to generate $€ 103$ more revenue per lactation than the best cows ranked on the EBI. Milk solids yield was also greater for the higherranking cows in both indices. This may be an artifact of earlier-calving cows having a greater lactation length potential, but also superior genetic merit for higher milk solids (Table 4). The milk pricing system in Ireland rewards producers for higher milk solids and penalizes for volume. The prevailing payment is set at $€ 8.07$ per $\mathrm{kg}$ of protein, $€ 2.83$ per $\mathrm{kg}$ of fat, and $-€ 0.07$ per liter of milk volume. The difference in revenue between the best quartile and worst quartile of cows on the COW index was €360 per lactation. Cows in the top quartile had an average yield of $7,174 \mathrm{~L}$ and produced $548 \mathrm{~kg}$ of milk solids, valued at $€ 2,391$; cows in the worst percentile group only averaged $6,349 \mathrm{~L}$ milk, containing 470 $\mathrm{kg}$ of milk solids, at a value of $€ 2,031$. The difference in revenue between the best and worst quartile of cows ranked on the EBI was only $€ 179$, attributable to the smaller difference in milk volume and milk solids yield between the groups. The difference in revenue between the best and worst cows on the COW index was more pronounced (€360), showing that the COW index was a more accurate measure of phenotypic milk performance than the EBI. 


\section{Deployment and Implementation of the COW Index}

For the purposes of this study, it was assumed that the COW index of females was generated the day immediately postcalving. The opportunity exists, however, to generate the COW index of a female at any time of the year incorporating all current information available. In particular, COW index values could be recalculated coinciding with the timing of national genetic evaluations when EBV, heterosis effects, recombination loss effects, and permanent environmental effects are re-estimated. As the breeding season progresses, additional knowledge is generated on expected month of calving in the subsequent lactation. For example, a cow inseminated in the middle of June, irrespective of her total genetic merit for fertility, is very unlikely to calve in February the following lactation; this can be further refined once pregnancy diagnosis data becomes available and information on fetal age (and thus more precise expected calving month) exists. Pregnancy diagnosis in seasonal calving herds usually occurs after the breeding season (Berry et al., 2013); therefore, if the pregnancy diagnosis reveals that the cow is not pregnant, then it may be assumed that she will not survive to the next lactation and the future lactation component of the COW index is set to zero. Additionally, the effect of the use of sexed semen will also alter expected profit for the next lactation. The future dairy replacement component of the COW index can be adjusted before a decision on whether or not X- or Y-bearing semen will be used. If pregnancy diagnosis or insemination information (i.e., farmer used Y-bearing semen) reveals that the fetus is male, then the probability that her calf in the next lactation will enter the herd as a dairy replacement can be set to zero; mate EBV for calving difficulty can also be used to modify the EPV of the cow for expected calving difficulty in the subsequent lactation. The decision to cull or retain a cow is generally made at the end of the breeding season after pregnancy diagnosis, and in seasonal breeding herds immediately before the breeding season (decision on whether or not to attempt to put the cow in calf). Because of the highly seasonal timing of breeding in Ireland (Berry et al., 2013), this implies that April and September may be a logical time of the year to generate these indices for aiding producers in decision making. This can also coincide with the generation of new genetic evaluations, but also the introduction of new economic weights following the annual review of the national breeding goal.

The net margin value on the different components of the COW index can also be easily modified to align with the production system of the farm. The initiation of the grass-growing season in Ireland differs by geo- graphical location (Brereton et al., 1996); therefore, the relative differences between months in average expected profit could be altered by farm to reflect this farm-tofarm variation. Furthermore, the milk pricing system in Ireland is tiered based on SCC; thus, the relative economic importance of SCC could be altered depending on the mean herd bulk tank SCC. Prior to attending a sale of potential replacement animals, the producer could modify the parameters in the COW index values of the potential replacements and the most suitable animals identified and the threshold price that could be paid for each animal determined. Furthermore, the relevance of the current economic values in the national breeding goal is evaluated annually and, where necessary, amended. Such amendments, including changes in prevailing milk prices (for current lactation component of the index), should be incorporated into the COW index simultaneously with their incorporation into revisions of the EBI.

Developments in the use of genomic information in genetic evaluations can also aid in improving the precision of the COW (and EBI) index. Genomic evaluations to date have predominantly focused on the estimation of additive allelic effects, which will improve the accuracy of the EBV component of the COW index; this essentially is the EBI and thus represents $42 \%$ of the emphasis in the COW index. A heterosis and recombination loss effect common to all animals of a given breed cross is currently estimated in the national genetic evaluations and subsequently used in the generation of the COW index; the extent of heterosis, and thus its effect, is likely to differ by animal (mating). In some of the genetic evaluations in Ireland, the heterosis coefficients from alternative breed crosses are combined into a single coefficient to improve the precision of the associated regression coefficients estimated in the genetic evaluations. Genomics should aid in better quantification of individual animal heterosis effects through the estimation of genotype effects incorporating both additive and dominance effects (Sun et al., 2013). This information can also be used in designing genomic matings to maximize performance of the resulting progeny both for additive and nonadditive genetic merit (Sun et al., 2013).

The approach derived in the present study to assist dairy producers with cow culling and purchase decisions constitutes a major departure from the complex decision-support tools that have received much attention in the literature. The COW index can be generated from the central database of dairy records and delivered in report format either in printed form, or as an interactive web-based interface. The COW index can also be expanded as additional phenotypes, such as 
animal health, are recorded and stored in the central database. Although options exist for regular updates through the calendar year, and for customization if sufficient information exists to customize the transition probabilities to particular herds, or types of herds or multiple management scenarios, the benefits are likely to be modest relative to the gains from using the $\mathrm{COW}$ index in a standard format compared with crude culling criteria or culling based on additive genetic merit prediction alone.

\section{CONCLUSIONS}

Tools already exist to identify females as suitable parents of the next generation. Few tools exist, however, to identify the least-profitable females for culling and most-profitable animals for purchasing. Culling is a function of total genetic merit as well as nongenetic attributes of the cow, such as age and season of calving. Outlined herein is a framework for a tool to rank females on expected profit for the remainder of their lifetime taking cognizance of all the important contributing factors to the cow herself as well as herd dynamics. Cows ranking highest on the COW index were not necessarily the females of the greatest additive genetic merit (and thus not the best females for selection as parents of the next generation), but, on average, calved at the most optimal period of the year, produced the greater quantity of milk, and were more likely to survive to the subsequent lactation.

\section{REFERENCES}

Ahlborn-Breier, G., and W. D. Hohenboken. 1991. Additive and nonadditive genetic effects on milk production in dairy cattle: Evidence for major individual heterosis. J. Dairy Sci. 74:592-602.

Amer, P. R., G. Simm, M. G. Keane, M. G. Diskin, and B. W. Wickham. 2001. Breeding objectives for beef cattle in Ireland. Livest. Prod. Sci. 67:223-239.

Beaudeau, F., J. D. van der Ploeg, B. Boileau, H. Seegers, and J. P. T. M. Noordhuizen. 1996. Relationships between culling criteria in dairy herds and farmers' management styles. Prev. Vet. Med. 25:327-342.

Ben-Ari, Y., I. Amir, and S. Sharar. 1983. Operational replacement decision model for dairy herds. J. Dairy Sci. 66:1747-1759.

Berry, D. P., F. Buckley, P. Dillon, R. D. Evans, M. Rath, and R. F. Veerkamp. 2003. Estimation of genotype $\times$ environment interactions, in a grass-based system, for milk yield, body condition score, and body weight using random regression models. Livest. Prod. Sci. 83:191-203.

Berry, D. P., B. L. Harris, A. M. Winkelman, and W. Montgomerie. 2005. Phenotypic associations between traits other than production and longevity in New Zealand dairy cattle. J. Dairy Sci. 88:2962-2974.

Berry, D. P., J. F. Kearney, K. Twomey, and R. D. Evans. 2013. Genetics of reproductive performance in seasonal calving dairy cattle production systems. Ir. J. Agric. Food Res. 52:1-16.

Berry, D. P., F. E. Madalena, A. R. Cromie, and P. R. Amer. 2006. Cumulative discounted expressions of dairy and beef traits in cattle production systems. Livest. Sci. 99:159-174.
Berry, D. P., L. Shalloo, A. R. Cromie, R. F. Veerkamp, P. Dillion, P. R. Amer, J. F. Kearney, R. D. Evans, and B. Wickham. 2007. The economic breeding index: A generation on. Technical report to the Irish Cattle Breeding Federation. Accessed Dec. 23, 2014. http:// www.icbf.com/publications/files/economic_breeding_index.pdf.

Berry, D. P., E. Wall, and J. E. Pryce. 2014. Genetics and genomics of reproductive performance in dairy and beef cattle. Animal 8:105-121.

Brereton, A. J., S. A. Danielov, and D. Scott. 1996. Agrometeorology of grass and grasslands for middle latitudes. Technical Note No. 197. World Meteorological Organization, Geneva, Switzerland.

Buckley, F., N. Lopez-Villalobos, and B. J. Heins. 2014. Crossbreeding: Implications for dairy cow fertility and survival. Animal 8(Suppl.1):122-133.

Clark, B. J., J. G. Garcia-Muniz, P. J. Black, and N. Lopez-Villalobos. 2013. Does production worth and breeding worth reflect cow profitability? Pages 17-20 in Proc. New Zeal. Soc. Anim. Prod., Hamilton, New Zealand. New Zealand Society of Animal Production, Hamilton, New Zealand.

Dijkhuizen, A. A., J. Stelwagen, and J. A. Renkema. 1986. A stochastic model for the simulation of management decisions in dairy herds, with special reference to production, reproduction, culling and income. Prev. Vet. Med. 4:273-289.

Falconer, D. S., and T. F. C. Mackay. 1996. Introduction to Quantitative Genetics. 4th ed. Longman, Essex, UK.

Fetrow, J., K. V. Nordlund, and H. D. Norman. 2006. Invited review: Culling: Nomenclature, definitions, and recommendations. J. Dairy Sci. 89:1896-1905.

Gamerman, D., and H. F. Lopes. 2006. Markov Chain Monte Carlo: Stochastic simulation for Bayesian inference. 2nd ed. Chapman \& Hall/CRC, Boca Raton, FL.

Hadley, G. L., C. A. Wolf, and S. B. Harsh. 2006. Dairy cattle culling patterns, explanations, and implications. J. Dairy Sci. 89:22862296 .

Harris, B. L. 2005. Breeding dairy cows for the future in New Zealand. N. Z. Vet. J. 53:384-390.

Harris, B. L., A. M. Winkelman, and D. E. Johnson. 2014. Acrossbreed genomic prediction in dairy cattle. In Proc. 10th World Congr. Genet. Appl. Livest. Prod. Vancouver, Canada.

Hoeschele, I. 1991. Additive and nonadditive genetic variance in female fertility of Holsteins. J. Dairy Sci. 74:1743-1752.

Horan, B., P. Dillon, D. P. Berry, P. O'Connor, and M. Rath. 2005. The effect of strain of Holstein-Friesian, feeding system and parity on lactation curves characteristics of spring-calving dairy cows. Livest. Prod. Sci. 95:231-241.

ICBF. 2014. Understanding the EBI. Irish Cattle Breeding Federation. Accessed Dec. 23, 2014. http://www.icbf.com/wp/wp-content/uploads/2013/07/Understanding-EBI-PTA-BV-Spring-2014.pdf.

Jarrige, R., ed. 1989. Ruminant Nutrition, Recommended Allowances and Feed Tables. John Libbey Eurotext, Montrougue, France.

Kruuk, L. E. B., and J. D. Hadfield. 2007. How to separate genetic and environmental causes of similarity between relatives. J. Evol. Biol. 20:1890-1903.

Lehenbauer, T. W., and J. W. Oltjen. 1998. Dairy cow culling strategies: Making economical culling decisions. J. Dairy Sci. 81:264271.

LIC. 2014. Livestock Improvement Corporation. Accessed Dec. 23, 2014. www.lic.co.nz.

Lopez-Villalobos, N., M. Penasa, R. Dal Zotto, M. Cassandro, W. Brade, O. Distl, R. Evans, and A. Cromie. 2010. Calculation of a cow culling merit index including specific heterosis in a multibreed dairy population. Arch. Tierz. 53:9-17.

LTO. 2014. LTO International milk price comparison. LTO Nederland. Accessed Dec. 23, 2014. http://www.milkprices.nl/.

Nielsen, L. R., E. Jørgensen, A. R. Kristensen, and S. Østergaard. 2010. Optimal replacement policies for dairy cows based on daily yield measurements. J. Dairy Sci. 93:75-92.

Pabiou, T., W. F. Fikse, P. R. Amer, A. R. Cromie, A. Näsholm, and D. P. Berry. 2012. Genetic relationships between carcass cut weights predicted from video image analysis and other performance traits in cattle. Animal 6:1389-1397. 
Penasa, M., N. López-Villalobos, R. D. Evans, A. R. Cromie, R. Dal Zotto, and M. Cassandro. 2010. Crossbreeding effects on milk yield traits and calving interval in spring-calving dairy cows. J. Anim. Breed. Genet. 127:300-307.

SAS Institute. 2011. SAS/STAT 9.3 User's Guide. Ver. 9.3 ed. SAS Institute Inc., Cary, NC.

Shalloo, L., A. Cromie, and N. McHugh. 2014. Effect of fertility on the economics of pasture-based dairy systems. Animal 8(Suppl. 1):222-231

Shalloo, L., P. Dillon, M. Rath, and M. Wallace. 2004. Description and validation of the Moorepark Dairy System Model. J. Dairy Sci. $87: 1945-1959$.

Sørensen, M. K., E. Norberg, J. Pedersen, and L. G. Christensen. 2008 Invited review: Crossbreeding in dairy cattle: A Danish perspective. J. Dairy Sci. 91:4116-4128.
Stewart, H. M., E. B. Burnside, J. W. Wilton, and W. C. Pfeiffer. 1977. A dynamic programming approach to culling decisions in commercial dairy herds. J. Dairy Sci. 60:602-617.

Sun, C., P. M. VanRaden, J. R. O'Connell, K. A. Weigel, and D. Gianola. 2013. Mating programs including genomic relationships and dominance effects. J. Dairy Sci. 96:8014-8023.

Swan, A. A., and B. P. Kinghorn. 1992. Evaluation and exploitation of crossbreeding in dairy cattle. J. Dairy Sci. 75:624-639.

Veerkamp, R. F., and S. Brotherstone. 1997. Genetic correlations between linear type traits, food intake, live weight and condition score in Holstein Friesian dairy cattle. Anim. Sci. 64:385-392.

Weigel, K. A., R. W. Palmer, and D. Z. Caraviello. 2003. Investigation of factors affecting voluntary and involuntary culling in expanding dairy herds in Wisconsin using survival analysis. J. Dairy Sci. $86: 1482-1486$ 